\title{
Acute cardiovascular effects of the Wenchuan earthquake: ambulatory blood pressure monitoring of hypertensive patients
}

\author{
Yucheng Chen ${ }^{1,5}$, Jing $\mathrm{Li}^{2,5}$, Hong Xian ${ }^{3}$, JiangBo $\mathrm{Li}^{1}, \mathrm{Si} \mathrm{Liu}^{4}$, GuanJian Liu ${ }^{2}$, JianNan $\mathrm{Lin}^{1}$, Jun Han ${ }^{1}$ \\ and Zhi Zeng ${ }^{1}$
}

An increased incidence of cardiovascular events and sudden death occurs after an earthquake. However, the mechanism underlying this is not clear. Previous studies attributed this phenomenon to earthquake-induced elevation of sympathetic activity. This study investigated the acute cardiovascular effects of the Wenchuan earthquake on hypertensive or suspected hypertensive patients. We studied the role of earthquake-induced changes in blood pressure and heart rate in the occurrence of post-earthquake cardiovascular events. This study included 11 patients who were undergoing ambulatory blood pressure monitoring when the Wenchuan earthquake occurred. Trends in blood pressure and heart rate were analyzed, and blood pressure variability (BPV) data were obtained. The mean post-earthquake blood pressure rose rapidly from $125.8 \pm 17.3 / 72.1 \pm 11.9$ to $150.5 \pm 20.3 / 98 \pm 10.6 \mathrm{~mm} \mathrm{Hg}$ (average time of first measurement was $13.8 \pm 6.3 \mathrm{~min}$ after the first tremor), and blood pressure remained high until $6 \mathrm{~h}$ after the earthquake. Nighttime blood pressure declined to the mean pre-earthquake daytime levels. The mean daytime blood pressure after the earthquake was greater than the pre-earthquake daytime mean (systolic blood pressure: $138.9 \pm 14.6$ vs. $129.5 \pm 13.6 \mathrm{~mm} \mathrm{Hg}, P=0.009$; diastolic blood pressure (DBP): $81.8 \pm 13.1$ vs. $76.9 \pm 11.9 \mathrm{~mm} \mathrm{Hg}$, $P=0.011$ ). Pre- and post-earthquake BPV differed among individuals, but circadian variation was absent in all cases and nightly decreases were less than $10 \%$. These data strongly suggest that significant post-earthquake elevation of blood pressure and abnormal circadian variation of blood pressure are related to the occurrence of post-earthquake cardiovascular events. Hypertension Research (2009) 32, 797-800; doi:10.1038/hr.2009.98; published online 10 July 2009

Keywords: ambulatory blood pressure monitoring (ABPM); cardiovascular effects; Wenchuan earthquake

\section{INTRODUCTION}

Emotional stress has a remarkable effect on the cardiovascular system, and a positive relation between acute or chronic stress and the occurrence of cardiovascular disease has been established. ${ }^{1-3}$ Earthquakes are catastrophic natural events producing high levels of stress. Several studies have shown increased numbers of sudden cardiac-related deaths after an unpredicted earthquake, especially on the day of the earthquake's occurrence. ${ }^{4-6}$ However, the specific mechanisms underlying this phenomenon remain unclear. Some studies have attributed the deaths to the impact of a major emotional stress on the heart, mediated through an increase in cardiac sympathetic activity. ${ }^{6,7}$ Other studies have targeted the rapid rise in blood pressure after an earthquake, as in the earthquakes that affected Texas City in $1948,{ }^{8}$ Wyoming Valley in $1980,{ }^{9}$ and the Hanshin-Awaji earthquake in Japan in January 1995. ${ }^{10}$ Kario et al. ${ }^{11}$ reported that blood pressure levels increased during the 1-2 weeks after the Hanshin-Awaji earthquake in elderly hypertensive patients, and returned to baseline levels within $3-5$ weeks after the earthquake. Earthquake-induced increase in blood pressure was also associated with acute potentiation of cardiovascular risk factors, such as blood viscosity determinants and fibrin turnover, and prolongation of endothelial cell stimulation, ${ }^{12}$ which contributed to the occurrence of cardiovascular events after the earthquake.

However, most current information on the cardiovascular effects of an earthquake is based on indirect evidence, such as comparison of blood pressure before and a few weeks after the earthquake. One exception is a case report using direct evidence from ambulatory blood pressure monitoring (ABPM), ${ }^{13}$ although this study is subject to the obvious technical difficulties in taking ambulatory blood pressure during an earthquake. The authors found substantial individual variations in blood pressure in response to the acute stress. This single case, however, cannot be taken to represent the post-earthquake cardiovascular effects in general.

\footnotetext{
${ }^{1}$ Department of Cardiology, West China Hospital, Sichuan University, Chengdu, Sichuan, PR China; ${ }^{2}$ The Chinese Cochrane Center, West China Hospital, Sichuan University, Chengdu, Sichuan, PR China; ${ }^{3}$ Department of Geriatrics, West China Hospital, Sichuan University, Chengdu, Sichuan, PR China and ${ }^{4}$ Department of Public Management, West China Hospital, Sichuan University, Chengdu, Sichuan, PR China

${ }^{5}$ These authors contributed equally to this work.

Correspondence: Professor Z Zeng, Division of Cardiology, West China Hospital, Sichuan University, Chengdu 610041, Sichuan, PR China. E-mail: zengzhi1954@hotmail.com
}

Received 2 December 2008; revised 30 May 2009; accepted 4 June 2009; published online 10 July 2009 
This study thus presents data associated with the Wenchuan earthquake, reporting the acute effects of this stressful event on the blood pressure and heart rate of 11 patients who were undergoing 24-h ABPM. The earthquake registered 8.0 on the Richter scale and struck the Wenchuan region of Sichuan Province, China, on 12 May 2008. To our knowledge, this is the largest analysis of patients with ABPM records during an earthquake. These invaluable data will help us better understand the characteristics and mechanisms of earthquake-induced increases in blood pressure and heart rate.

\section{METHODS}

\section{The Wenchaun earthquake}

At 1428 hours Beijing time (0628 hours GMT) on 12 May 2008, an earthquake measuring 8.0 on the Richter scale struck Wenchuan County, Sichuan Province, China. The epicenter was in Wenchuan County, Ngawa Tibetan and Qiang Autonomous Prefecture, $80 \mathrm{~km}$ west/northwest of the provincial capital city of Chengdu. Neighboring cities such as Beichuan, Jiangyou, Tianpeng, Guangyuan, Mianyang and Chengdu suffered extensive damage and continuous aftershocks. People living in Chengdu felt an initial life-threatening tremor that lasted for 2-3 min. The Wenchuan earthquake released 30 times the energy of the Great Hanshin earthquake of 1995 in Japan that killed over 6000 people. As of 1200 hours on 24 July 2008, in the entire affected region, the death toll was 69197 , with 374176 people wounded, 18209 missing and 1485697 people moved to shelters.

\section{Patients}

This study included 11 patients (9 confirmed and 2 suspected hypertensive) from the West China Hospital (Chengdu, Sichuan Province). Seven were male and four were female, and the average age was $58.4 \pm 17.9$ years. Detailed patient profiles are shown in Table 1. All patients were performing ABPM on the day of the Wenchuan earthquake. The West China Hospital in Chengdu is $72 \mathrm{~km}$ from the earthquake's epicenter, and all the participants experienced the earthquake at 5.9 on the Richter scale. On the next day of the Wenchuan earthquake, the recorded data of ABPM were obtained successfully. In addition to these data, we reviewed the case records of all patients, including brief medical history, blood pressure in a clinical setting, drug use and coexisting diseases. All patients gave informed consent and the Medical Ethics Committee of West China Hospital in Sichuan University approved the study.

\section{Ambulatory blood pressure monitoring}

Noninvasive ABPM was carried out almost over a 24-h period with an oscillometric SpaceLabs 90217 (Spacelabs Medical, Issaquah, WA, USA), validated by the standard criteria of the Association for the Advancement of Medical Instrumentation and the British Hypertension Society (http://www. dableducational.com). Blood pressure was recorded on the nondominant arm using an appropriately sized cuff. Blood pressure and heart rate were recorded every 20 or $30 \mathrm{~min}$ during the daytime (defined as from 0800 to 2200 hours) and every hour at nighttime (defined as from 2200 to 0800 hours). After all the recordings were obtained, the mean blood pressure \pm s.d. of pre-quake during the daytime, mean blood pressure \pm s.d. of post-quake during the daytime and mean blood pressure \pm s.d. during the nighttime were calculated. Furthermore, blood pressure variability (BPV) and circadian variation were analyzed.

\section{Definitions used in this study}

Blood pressure variability was defined as the s.d. of mean blood pressure during a period. In this study, pre-quake BPV was defined as the s.d. before the quake during the daytime, post-quake BPV as the s.d. after the quake during the daytime and diurnal BPV as the s.d. during the nighttime. Furthermore, diurnal blood pressure dip was investigated using the following equation: ((mean daytime mean arterial pressure (MAP) - mean nighttime MAP)/mean daytime MAP) $\times 100 \%$. If blood pressure dropped by more than $10 \%$ at night, it was termed 'dipper' mode, and if the decline was less than $10 \%$, it was termed 'non-dipper.' ${ }^{14}$

\section{Statistical analysis}

Quantitative data are expressed as mean \pm s.d. Changes in the pre- and postearthquake values of all parameters were analyzed using a two-way analysis of variance (ANOVA), with time and blood pressure as co-variables. The level of statistical significance level was set at 0.05 .

\section{RESULTS}

\section{Dynamic changes of blood pressure after the earthquake}

The average systolic blood pressure (SBP) $1 \mathrm{~h}$ before the earthquake was $125.8 \pm 17.3 \mathrm{~mm} \mathrm{Hg}$, and the average diastolic blood pressure (DBP) was $72.1 \pm 11.9 \mathrm{~mm} \mathrm{Hg}$ (Figure 1). After the earthquake, the mean blood pressure rose rapidly to $150.5 \pm 20.3 / 98 \pm 10.6 \mathrm{~mm} \mathrm{Hg}$ (the average time for first recording of blood pressure was $13.8 \pm 6.3 \mathrm{~min}$ after the first tremor), and the elevated blood pressure was sustained until $6 \mathrm{~h}$ after the earthquake. At night, the mean blood pressure declined to the mean pre-earthquake daytime levels. However, the data show a marked increase at 0500 hours after the fall at night. Several blood pressure peaks appeared on the day of the earthquake, namely between 0800 and 0900 hours on 12 May $(144.5 \pm 19.3 / 84.9 \pm 8.6 \mathrm{~mm} \mathrm{Hg})$, immediately after the earthquake $(150.5 \pm 20.3 / 98 \pm 10.6 \mathrm{~mm} \mathrm{Hg})$, between 1700 and 1800 hours on 12 May (148.9 $\pm 13.6 / 8.0 \pm 17.3 \mathrm{~mm} \mathrm{Hg}$; approximately $3 \mathrm{~h}$ post-earthquake), and between 2100 and 2200 hours on 12 May (143.4 $\pm 22.6 /$ $82.3 \pm 11.5 \mathrm{~mm} \mathrm{Hg}$; approximately $6 \mathrm{~h}$ post-earthquake). After 2200 hours, blood pressure slowly declined to the mean pre-earthquake level. Blood pressure rose again the next morning.

\section{Comparison of blood pressure before and after the earthquake}

The total ABPM recording time was divided into three sections: daytime before the earthquake (0800-1428 hours Beijing time),

\section{Table 1 Clinical profiles of patients in this study}

\begin{tabular}{|c|c|c|c|c|c|}
\hline Patients no. & Sex & Age (years) & Final diagnosis & Coexisting disease & Drug \\
\hline 1 & M & 60 & Hypertension & 2-DM & No treatment \\
\hline 2 & $\mathrm{~F}$ & 68 & Normotension & None & No treatment \\
\hline 3 & M & 39 & Hypertension & None & No treatment \\
\hline 4 & $\mathrm{~F}$ & 70 & Hypertension & None & Amlodipine \\
\hline 5 & $\mathrm{~F}$ & 45 & Hypertension & None & No treatment \\
\hline 6 & M & 43 & Hypertension & None & Amlodipine, metoprolol \\
\hline 7 & $\mathrm{M}$ & 83 & Normotension & CHD, stroke, COPD & Aspirin, statin, clopidogral \\
\hline 8 & M & 79 & Hypertension & CHD, stroke & Metoprolol, clopidogral, irbesartan \\
\hline 9 & $\mathrm{~F}$ & 79 & Hypertension & CHD, COPD, 2-DM & Irbesartan, statin, nifedipine \\
\hline 10 & M & 63 & Hypertension & 2-DM & Metformin, avandia, metoprolol, irbesartan, aspirin \\
\hline 11 & M & 57 & Hypertension & 2-DM, AF & Metformin, nifedipine, aspirin \\
\hline
\end{tabular}

Abbreviations: 2-DM, type 2 diabetes mellitus; AF, atrial fibrillation; CHD, coronary heart disease; COPD, chronic obstructive pulmonary disease; F, female; M, male. 
post-earthquake daytime (1428-2200 hours Beijing time) and postearthquake nighttime (2200-0800 hours Beijing time). We also collected blood pressure data immediately after the earthquake, recording the average value of two consecutive initial post-earthquake measurements. The mean blood pressure immediately after the earthquake was significantly greater than that before the earthquake (SBP: $148.8 \pm 17.1$ vs. $129.5 \pm 13.6 \mathrm{~mm} \mathrm{Hg}, P=0.000$; DBP: $88.5 \pm 11.7$ vs. $76.9 \pm 11.9 \mathrm{~mm} \mathrm{Hg}, P=0.000)$. The average daytime blood pressure after the earthquake (1428-2200 hours) was significantly greater than the pre-earthquake daytime mean (SBP: $138.9 \pm 14.6$ vs. $129.5 \pm$ $13.6 \mathrm{~mm} \mathrm{Hg}, \quad P=0.009 ; \quad$ DBP: $81.8 \pm 13.1$ vs. $76.9 \pm 11.9 \mathrm{~mm} \mathrm{Hg}$, $P=0.011)$. The average nighttime blood pressure after the earthquake decreased significantly in comparison with the average daytime blood pressure after the earthquake (SBP: $130.5 \pm 16.8$ vs. $138.9 \pm$ $14.6 \mathrm{~mm} \mathrm{Hg}, P=0.018$; DBP: $74.6 \pm 12.4$ vs. $81.8 \pm 13.1 \mathrm{~mm} \mathrm{Hg}$, $P<0.01)$. However, there was no significant difference in mean blood pressure between the night after the earthquake and the daytime mean before the earthquake (SBP: $130.5 \pm 16.8$ vs. $129.5 \pm$ $13.6 \mathrm{~mm} \mathrm{Hg}, \quad P=0.77 ; \quad \mathrm{DBP}: \quad 74.6 \pm 12.4$ vs. $76.9 \pm 11.9 \mathrm{~mm} \mathrm{Hg}$, $P=0.21$ ) (Figure 2).

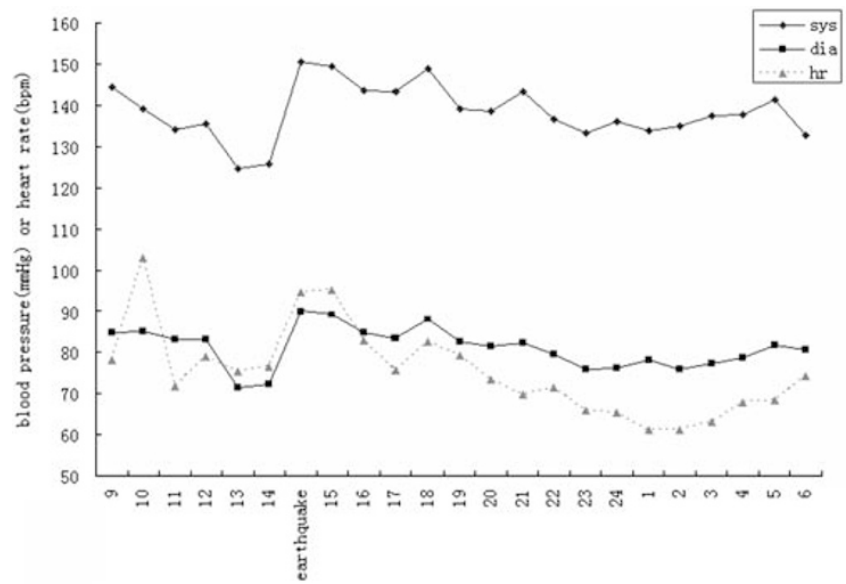

Figure 1 Twenty-four-hour dynamic changes in blood pressure and heart rate on the day of the Wenchuan earthquake. Systolic blood pressure, diastolic blood pressure and heart rate were recorded by 24-h ambulatory blood pressure monitoring in patients on 12 May 2008. dia, diastolic blood pressure; hr, heart rate; sys, systolic blood pressure.

\section{BPV and circadian variation analysis}

Individual BPV after the earthquake increased in four cases, decreased in six cases and remained unchanged in one case. However, in the whole group, there was no significant change in BPV between that before the quake and that after the quake (s.d. of SBP during the daytime before the quake vs. daytime after the quake: $13.9 \pm 3.8 v s$. $12.1 \pm 2.8 \mathrm{~mm} \mathrm{Hg} ; P=0.21$; s.d. of SBP during the daytime before the quake $v s$. nighttime after the quake: $13.9 \pm 3.8$ s. $11.1 \pm 4.0 \mathrm{~mm} \mathrm{Hg}$; $P=0.18$; s.d. of DBP during the daytime before the quake vs. daytime after the quake: $9.7 \pm 3.1$ vs. $7.9 \pm 2.1 \mathrm{~mm} \mathrm{Hg} ; P=0.11$; s.d. of DBP during the daytime before the quake $v s$. nighttime after the quake: $9.7 \pm 3.1$ vs. $7.9 \pm 3.4 \mathrm{~mm} \mathrm{Hg} ; P=0.23$ ). As shown in Table 2, the nocturnal decline in blood pressure after the earthquake was less than $10 \%$ of the daytime blood pressure before the quake for all patients. Therefore, the physiological circadian variation of blood pressure disappeared in all cases and was classified as the 'non-dipper' type.

\section{Changes in heart rate after the earthquake}

The earthquake induced a significant increase in the mean heart rate in comparison with the pre-earthquake mean $(94.6 \pm 11.1 \mathrm{vs}$. $75.1 \pm 10.8$ b.p.m., $P=0.000)$. The mean heart rate then declined rapidly to the pre-earthquake mean within $1 \mathrm{~h}$. Thereafter, the average daytime heart rates were similar before and after the earthquake (78.5 \pm 10.0 vs. $75.1 \pm 10.8, P=0.204)$. The nighttime mean heart

Table 2 Circadian variation of blood pressure in patients on the day of the earthquake

\begin{tabular}{lccc}
\hline $\begin{array}{l}\text { Patients } \\
\text { no. }\end{array}$ & $\begin{array}{c}\text { MAP during daytime } \\
\text { (mean } \pm \text { s.d. } \mathrm{mm} \mathrm{Hg} \text { ) }\end{array}$ & $\begin{array}{c}\text { MAP during nighttime } \\
\text { (mean } \pm \text { s.d. } \mathrm{mm} \mathrm{Hg})\end{array}$ & $\begin{array}{c}\text { Decrease in noc- } \\
\text { turnal BP (\%) }\end{array}$ \\
\hline 1 & $135.3 \pm 9.6$ & $132 \pm 10.8$ & 2.2 \\
2 & $116.9 \pm 10.7$ & $108.4 \pm 9.2$ & 7.3 \\
3 & $106.8 \pm 12.3$ & $104.5 \pm 3.2$ & 2.2 \\
4 & $112.7 \pm 11.8$ & $105.6 \pm 10.7$ & 6.3 \\
5 & $134.5 \pm 11.6$ & $136.3 \pm 8.4$ & -1.3 \\
6 & $110.1 \pm 7.2$ & $103.9 \pm 5.4$ & 5.6 \\
7 & $104.2 \pm 12.3$ & $94.3 \pm 7.3$ & 9.5 \\
8 & $111.6 \pm 18.5$ & $100.8 \pm 16.0$ & 9.6 \\
9 & $112.8 \pm 25.8$ & $123.9 \pm 10.6$ & -9.8 \\
10 & $102.4 \pm 14.2$ & $113.5 \pm 8.3$ & -10.8 \\
11 & $125.4 \pm 15.6$ & $113.8 \pm 13.4$ & 9.2 \\
\hline
\end{tabular}

Abbreviations: BP, blood pressure; MAP, mean arterial pressure.
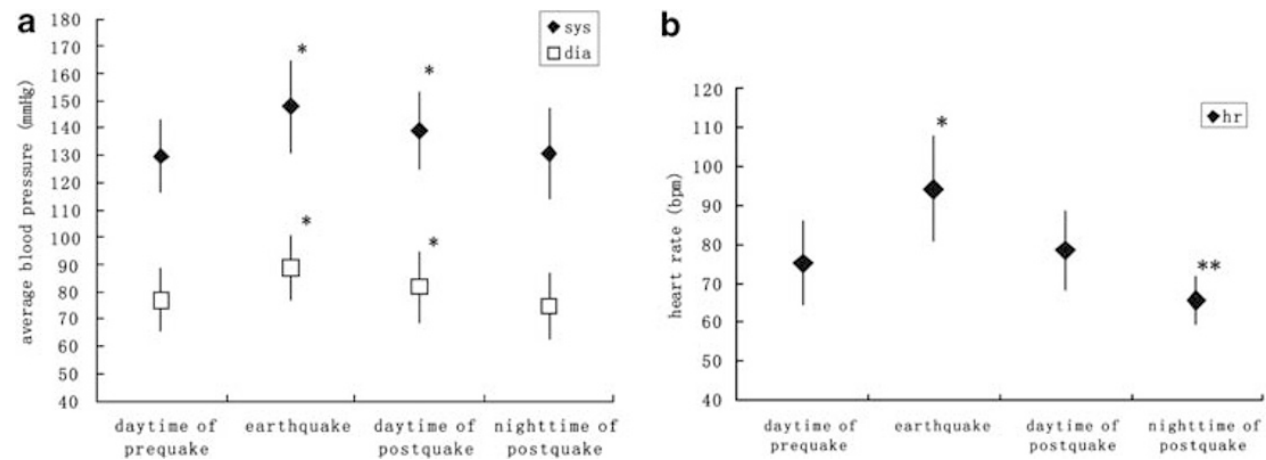

Figure 2 Comparison of mean blood pressure and heart rate before and after the earthquake. (a) Mean systolic and diastolic blood pressure. ${ }^{*} P<0.01$, compared with the mean blood pressure before the earthquake. (b) Mean heart rate on the day of the earthquake. ${ }^{*} P<0.01$, compared with the mean heart rate before the earthquake. ${ }^{*} P<0.05$, the difference between nighttime mean heart rate after the earthquake and mean heart rate before the earthquake. dia, diastolic blood pressure; hr, heart rate; sys, systolic blood pressure. 
rate was significantly lower than that during the daytime (heart rate during the nighttime vs. heart rate during the daytime before the quake: $65.7 \pm 6.2$ vs. $75.1 \pm 10.8$ b.p.m., $P=0.001$; heart rate during the nighttime $v s$. heart rate during the daytime after the quake: $65.7 \pm 6.2$ vs. $78.5 \pm 10.0, P=0.000)$.

\section{DISCUSSION}

We observed a substantial earthquake-induced increase in the mean blood pressure and heart rate immediately after the Wenchuan earthquake in 11 cases, regardless of age, sex and whether the patients were confirmed or suspected hypertensives. This indicates that the acute cardiovascular response to a catastrophic stress involves both cardiac and vascular stimulation, presumably triggered by an increase in sympathetic activity. ${ }^{8}$ This may represent a major pathophysiological mechanism responsible for the increased incidence of cardiovascular events and cardiac-related sudden death occurring immediately or within $1 \mathrm{~h}$ after an earthquake, as shown in association with the 1994 Northridge earthquake. ${ }^{6,15}$ In all patients, the increased blood pressure gradually declined within $6 \mathrm{~h}$ after the earthquake. This is in contrast to report of Parati et al. ${ }^{13}$ suggesting that increased blood pressure lasted only for $1 \mathrm{~h}$. In addition, our patients' blood pressure increased again at 2100 hours (Beijing time) on the day of the Wenchuan earthquake. The long-lasting high blood pressure might be attributed to disabled communication abilities until 2000-2100 hours (Beijing time) and to repeated aftershocks throughout the day. Such mental stress induces a remarkable elevation of heart rate and blood pressure, which results in increased myocardial oxygen demand and vulnerable plaque rupture, ${ }^{16}$ and can also lead to reduced coronary oxygen supply. ${ }^{17}$ Our study provided direct evidence of heart rate and blood pressure elevation. The remarkable fluctuation of blood pressure that we observed immediately after the earthquake coincides with the previously reported timing of increased incidence of cardiac-related sudden death.

Our study showed that the earthquake-induced increase in blood pressure declined at night in comparison with the pre-earthquake mean blood pressure, but the decline was less than $10 \%$. This indicated an abnormal blood pressure circadian variation evidenced by the disappearance of nocturnal decrease in blood pressure, designated as the 'non-dipper' type. The earthquake-induced disruption of the usual 24-h diurnal rhythm might further contribute to an increase in cardiovascular events. Several studies have shown that the most notable increase in cardiac deaths occurs in the period from midnight to early morning after an earthquake. ${ }^{6,18,19}$ One study has also shown that the onset of acute myocardial infarction in the period from midnight to morning was more frequent in depressed patients than in those not suffering from depression. ${ }^{20}$ Earthquake-induced depression and sleeping impairment may be the reason for the elevation of sudden death cases at night. Kario et al. ${ }^{21}$ have also found that diurnal elevation of blood pressure was affected by sub-clinical depression. Therefore, there is a clear link among earthquake-induced depression, diurnal blood pressure elevation and increased incidence of sudden death at night after an earthquake.

\section{Limitations of this study}

The Wenchuan earthquake was an unanticipated natural disaster and it was very difficult to carry out a well-designed investigation. Our data, however, provide important information about earthquakeinduced acute cardiovascular effects. The limited number of cases did not allow us to perform multivariate analysis to explore the factors associated with earthquake-induced cardiovascular effects, such as age, sex, drug use and coexisting diseases. In addition, our study collected data only from the day of the earthquake. Investigation of the longterm effects of the earthquake on blood pressure and cardiovascular events requires further follow-up.

\section{Conclusions}

This study showed a rapid cardiovascular response to the earthquake, particularly increases in blood pressure and heart rate. In addition, the abnormal diurnal rhythm of blood pressure in hypertensive patients coincided with the known diurnal variation of earthquake-induced sudden death. These interesting results help us to better understand the increase in cardiovascular events after an earthquake, and suggest that non-pharmacological and pharmacological measures should be taken to control increased blood pressure and maintain the disrupted diurnal rhythm in an effort to interrupt the link between earthquakeinduced stress and cardiovascular events.

\section{CONFLICT OF INTEREST}

The authors declare no conflict of interest.

1 McEwen BS. Protective and damaging effects of stress mediators. N Engl J Med 1998; 338: $171-179$.

2 Rozanski A, Blumenthal JA, Kaplan J. Impact of psychological factors on the pathogenesis of cardiovascular disease and implications for therapy. Circulation 1999; 99: 2192-2217.

3 Kario K, Mcewen BS, Pickering TG. Disasters and the heart: a review of the effects of earthquake-induced stress on cardiovascular disease. Hypertens Res 2003; 26: 355-367.

4 Trichopoulos D, Katsouyanni K, Zavitsanos X, Tzonou A, Dalla-Vorgia P. Psychological stress and fatal heart attack: the Athens (1981) earthquake natural experiment. Lancet 1983; 1: 441-444.

5 Dobson AJ, Alexander HM, Malcolm JA, Steele PL, Miles TA. Heart attacks and the Newcastle earthquake. Med J Aust 1991; 155: 757-761.

6 Leor J, Poole WK, Kloner RA. Sudden cardiac death triggered by earthquake. N Eng/ J Med 1996; 334: 413-419.

7 Brown DL. Disparate effects of the 1989 Loma Prieta and 1994 Northridge earthquakes on hospital admissions for acute myocardial infarction: importance of superimposition of triggers. Am Heart J 1999; 137: 830-836.

8 Ruskin A, Beard OW, Schaffer RL. 'Blast hypertension' elevated arterial blood pressures in the victims of Texas city disaster. Am J Med 1948; 4: 228-236.

9 Logue JN, Hansen H. A case-control study of hypertensive women in a post-disaster community: Wyoming Valley, Pennsylvania. J Human Stress 1980; 6: 28-34.

10 Saito K, Kim JI, Maekawa K, Ikeda Y, Yokoyama M. The great Hanshin-Awaji earthquake aggravates blood pressure control in treated hypertensive patients. Am J Hypertens 1997; 10: 217-221.

11 Kario K, Matsuo T, Shimada K, Pickering TG. Factors associated with the occurrence and magnitude of earthquake-induced increases in blood pressure. Am J Med 2001; 111: 379-384.

12 Kario K, Matsuo T, Kobayashi H, Yamamoto K, Shimada K. Earthquake-induced potentiation of acute risk factors in hypertensive elderly patients: possible triggering of cardiovascular events after a major earthquake. J Am Coll Cardiol 1997; 29: 926-933.

13 Parati G, Antonicelli R, Guazzarotti F, Paciaroni E, Mancia G. Cardiovascular effects of an earthquake: direct evidence by ambulatory blood pressure monitoring. Hypertension 2001; 38: 1093-1095.

14 Henskens LH, van Oostenbrugge RJ, Kroon AA, de Leeuw PW, Lodder J. Brain microbleeds are associated with ambulatory blood pressure levels in a hypertensive population. Hypertension 2008; 51: 62-68.

15 Kloner RA, Leor J, Poole WK, Perritt R. Population-based analysis of the effect of the Northridge Earthquake on cardiac death in Los Angeles County, California. J Am Coll Cardiol 1997; 30: 1174-1180.

16 Muller JE, Abela GS, Nesto RW, Tofler GH. Triggers, acute risk factors and vulnerable plaques: the lexicon of a new frontier. J Am Coll Cardiol 1994; 23: 809-813.

17 Yeung AC, Vekshtein VI, Krantz DS, Vita JA, Ryan Jr TJ, Ganz P, Selwyn AP. The effect of atherosclerosis on the vasomotor responses of coronary ateries to mental stress. N Engl J Med 1991; 325: 1551-1556.

18 Kario K, Ohashi T, on behalf of Tsuna Medical Association. Increased coronary heart disease mortality after the Hanshin-Awaji earthquake among the older community on Awaji Island. J Am Geriatr Soc 1997; 45: 610-613.

19 Kario K, Ohashi T, on behalf of Tsuna Medical Association. After major earthquake, stroke death occurs more frequently than coronary heart disease death in very elderly subjects. J Am Geriatr Soc 1998; 46: 537-538.

20 Carney RM, Freedland KE, Jaffe AS. Altered circadian pattern of acute myocardial infarction in patients with depression. Coron Artery Dis 1991; 2: 61-65.

21 Kario K, Schwartz JE, Davidson KW, Pickering TG. Gender differences in associations of diurnal blood pressure variation, awake physical activity, and sleep quality with negative affect: the work site blood pressure study. Hypertension 2001; 38: 997-1002. 